\title{
Back to plastic pollution in COVID times
}

\author{
Giuliana Gorrasi ${ }^{1} \cdot$ Andrea Sorrentino $^{2} \cdot$ Eric Lichtfouse ${ }^{3,4}$ (1)
}

Published online: 7 November 2020

(c) Springer Nature Switzerland AG 2020

The great problem of social chemistry we call politics, is to discover what desires of mankind may be gratified, and what must be suppressed, if the highly complex compound, society, is to avoid decomposition

Thomas Huxley (1871)

In this article, we show that the chaos and urgency induced by the coronavirus disease 2019 (COVID-19) pandemic has led to massive fossil fuel-derived plastic production, largely ignoring recent environmental policies. Solutions for a sustainable and circular economy require radical innovations, consumer education and most importantly political willingness.

\section{The plastic evil}

The world health crisis caused by the spread of COVID-19 is not only damaging people's health and the world economy but is also threatening environmental sustainability (Sharma et al. 2020). Numerous media have warned about the ecological disaster caused by this pandemic (Canning-Clode et al. 2020; Aragaw 2020). For instance, there is a sharp increase in plastic waste from personal protective equipment such as masks and gloves, and from the massive return to using plastic shopping bags to prevent cross-contamination, whereas many nations had started to ban at least partly the use of non-biodegradable bags before the COVID era (Klemeš et al. 2020; Fadare and Okoffo 2020). Moreover,

\section{Giuliana Gorrasi}

ggorrasi@unisa.it

1 Department of Industrial Engineering, University of Salerno, Via Giovanni Paolo II 132, 84084 Fisciano, SA, Italy

2 Institute of Polymers, Composites and Biomaterials (IPCB), National Research Council of Italy (CNR), Via Previati 1/C, 23900 Lecco, Italy

3 Aix-Marseille Univ, CNRS, IRD, INRAE, Coll France, CEREGE, 13100 Aix en Provence, France

4 State Key Laboratory of Multiphase Flow in Power Engineering, Xi' an Jiaotong University, Xi' an 710049, China the lockdown has highly fostered e-commerce, resulting in massive consumption of materials for containment and packaging (Patrício Silva et al. 2021; Han et al. 2020). Medical waste has grown up to $370 \%$ and packaging plastic demand up to $40 \%$ (Patrício Silva et al. 2021). The fight against the virus has thus overshadowed environmental protection policies. For example, the recent drop of oil prices, which may appear as a benefit for drivers, has in fact prompted a real setback of policies aimed at reducing plastic materials of synthetic origin (Sun and Han 2020). We even observe the rise of opposing factions ready to challenge each other to prove their ideas: on one hand, some people think that plastic is the absolute evil to be eliminated in any way; on the other hand, others argue that it is impossible to change the current lifestyle (Czigany and Ronkay 2020). The truth is that both sides aim to solve a very complex problem with simplistic solutions. Indeed, plastic waste is a problem that simultaneously involves economic, social and technological aspects (Vanapalli et al. 2021; Prata et al. 2020). In other words, all society issues cannot be solved anymore by the painkiller approach in a globalized word, but required a new world system involving fast evaluation and actions taking into account all aspects of a problem (Lichtfouse 2009,2010; Lichtfouse et al. 2012).

\section{An old problem}

Long before the world knew about COVID-19, millions of tons of plastic ended up daily in the sea with serious damage to the environment and with an unacceptable waste of precious resources (Haward 2018). Macroscopic residues from the degradation of common objects such as bottles or food packaging are only a small percentage of these wastes (Wang et al. 2019; Tofa et al. 2019). The main part is represented by micro- and nanoparticles, e.g., microplastics, produced by common operations such as the discharge of wastewater from our washing machines, the use of cosmetics and detergents, and the consumption of car tires (Padervand et al. 2020; Naqash et al. 2020). Certainly, the solution cannot be solely to eliminate plastic materials, including those 
of synthetic origin. This would be a utopian solution, technically unsustainable and destined to succumb to multiple socioeconomic interests. Of course, this does not mean that any kind of behavior can be excused. There are millions of cotton swabs, toy balloons and drinking straws that end up on our beaches every year.

\section{Forgotten bioplastics}

The emergency caused by COVID-19 is highlighting, once again, the extreme fragility of our systems of management, disposal and recycling of plastic waste (Nanda and Berruti 2020a). To fight this health emergency, we have quickly needed large quantities of inexpensive, safe and easy-tofind materials. In the rush, the only choice available was to use petroleum-derived polymers such as polypropylene and polyethylene as disposable materials. This does not mean that alternatives based on biodegradable materials, often of natural origin, were not available (Brandelli et al. 2017). Indeed, scientists have recently made available various biodegradable polymers (Qasim et al. 2020; Amorim et al. 2020). Some biopolymers even display high performances and unique new functions compared to traditional materials (Morin-Crini et al. 2019). However, these biopolymers are not yet the first choice when there is a need for a quick and efficient response to a real problem. This is because, from a commercial point of view, these materials are still poorly known, expensive and often difficult to handle. Moreover, there are still no biorefineries capable of supplying high volumes of bioplastics fast, in a sustainable way and at competitive costs. Similarly, there are still too few companies able to recycle these materials. Furthermore, many scientists argue that the massive use of biodegradable materials could create serious issues for the few existing treatment plants (Wojnowska-Baryła et al. 2020; Meeks et al. 2015). Indeed, when working with expiring materials, it is not enough to produce and market them, but it is also necessary to plan their correct management, use and disposal. In the absence of adequate management plans, the massive use of biopolymers, in addition to being dangerous for consumers, may also become a problem for the environment.

\section{Political will}

The COVID-19 pandemic has disclosed the limits of the current economic system and challenged us to rethink and redesign this system into a more resilient, circular and lowcarbon economic model (Wuyts et al. 2020). The COVID19 crisis has revealed the brittleness of many global supply chains (Ibn-Mohammed et al. 2021; Sarkis et al. 2020). Here, circular principles such as recyclability and reusability offer credible solutions in terms of resilience and competitiveness (Fawzy et al. 2020). Maintaining the value of products, materials and resources for as long as possible by reinserting materials into the product cycle at the end of their use allows to minimize waste generation. However, the buildup of plastic recyclability is still a challenge because it requires specific regulations. In many countries, the use of waste as a raw material for other products is shrunk by regulations that prevent material transport and marketing. Changing these regulations typically leads to conflicts between stakeholders (Gunarathne et al. 2019). Similar conflicts arise when diverting biogenic waste streams from use in energy and composting to other uses (Nanda and Berruti 2020b). Today, we have all research and development capabilities to set up rapidly to new solutions and technologies on a large scale. Yet, what is still missing is a real political willingness to do so. As a consequence, the circular economy is much more than minimizing the production of waste or inventing biodegradable materials; the circular economy is a radically different economy, which overcomes the traditional conflicts between socioeconomic and environmental interests (Aldaco et al. 2020). Only when governments will set a clear direction for circular innovation in the private sector, will it be possible to combine economic regeneration, better social outcomes and climate ambitions.

\section{Additive manufacturing}

Much more effort must be dedicated to new materials and alternative production processes. Biodegradable materials must certainly continue to be developed. Low-cost, renewable materials with adequate properties and capable of rapid degradation in environment must be developed. New assembly and processing techniques are also necessary to avoid the inevitable shortcomings of new materials (Olivieri et al. 2020). For instance, additive manufacturing is a revolutionary technology that offers new freedom in materials employed and expands the range of possibilities for design, production and performances of novel products and systems (Sanchez-Rexach et al. 2020). In additive manufacturing, complex three-dimension objects are obtained with high precision by depositing materials in a layer-by-layer fashion. This provides several benefits such as the complete control of the object properties and significant savings in terms of time and cost (Balla et al. 2019).

\section{Circular economy}

From an economic point of view, it must be clear that any solution will fail without taking into account the benefit for all. For instance, incentive policies for the use of 


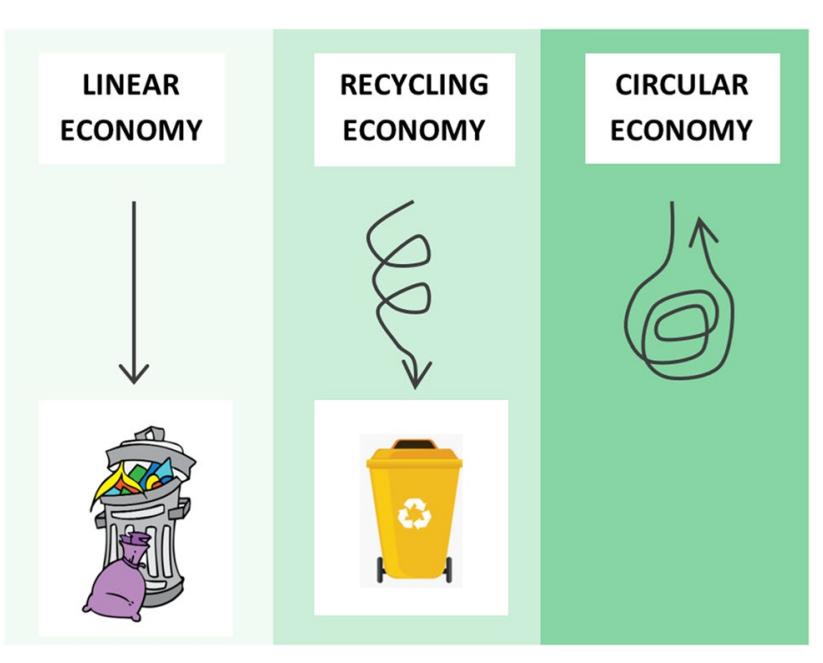

Fig. 1 Circular economy and waste management

bio-sustainable raw materials must be strengthened. Moreover, the calculated cost of a material cannot be only that of the raw material, but should take into account the impact on the environment. To do so, the whole production system must be considered, including waste generation, collection, transport, recycling and treatment, use of recovered resource and disposal of remains. Here, the circular approach allows both to reduce dependency on resource markets and decreases disposal costs (You et al. 2020) (Fig. 1). From a social point of view, the implementation of circular economies on a local basis can solve many problems related to the disasters produced by the uncontrolled globalization in recent decades. Bio-based products need new supply chains (Kosheleva et al. 2019) because the reduced life of bioproducts requires a denser location of production plants and strong collaborations between goods companies, retailers, consumers, waste management companies and legislators. This should induce social benefits such as increasing job creation at the local level and better employment conditions.

\section{Radical innovation}

We have to fundamentally rethink the value we assign to the objects of our everyday life (Prideaux et al. 2020) and get out of the 'I shop therefore I am' mantra evidenced by Barbara Kruger in 1987, to go back to the original quote 'I think therefore I am' from René Descartes in 1637. To do this, we need to understand the social and environmental values of products, and how to keep them in circulation for as long as possible (Milios et al. 2018). Designing products that are easier to disassemble and recycle and creating infrastructures that facilitate the return of products to manufacturers are also needed (Nithya et al. 2020). Radical innovation in an holistic way is thus critical to enable businesses and governments to reach their goals.

\section{Consumers psychology}

In the post-pandemic world, some of our COVID-19 habits will probably hang on for a long time. For example, e-commerce sales will continue to grow as many consumers will not give up on the benefits in terms of convenience and choice. This growth will lead to a significant increase in packaging material and associated problems of treatment and recycling. The COVID-19 pandemic is expected to spur a rapid transition to new models of circular economy. In particular, we need urgent and coordinated efforts to develop larger and more efficient systems and infrastructures for plastic waste management. Strict policies must force companies to reduce the use of natural materials in favor of those coming from recycling. In addition, working on the psychological aspects of consumers and encouraging sustainable products and processes through efficient tax policies would help to achieve sustainable development. Plastics are important because they provide many advantages, yet instead of demonizing, we should learn to use plastics responsibly.

\section{References}

Aldaco R, Hoehn D, Laso J, Margallo M, Ruiz-Salmón J, Cristobal J, Kahhat R, Villanueva-Rey P, Bala A, Batlle-Bayer L et al (2020) Food waste management during the COVID-19 outbreak: a holistic climate, economic and nutritional approach. Sci Total Environ $742: 140524$

Aragaw TA (2020) Surgical face masks as a potential source for microplastic pollution in the COVID-19 scenario. Mar Pollut Bull 159:111517

Balla VK, Kate KH, Satyavolu J, Singh P, Tadimeti JGD (2019) Additive manufacturing of natural fiber reinforced polymer composites: processing and prospects. Compos Part B Eng 174:106956

Brandelli A, Brum LFW, dos Santos JHZ (2017) Nanostructured bioactive compounds for ecological food packaging. Environ Chem Lett 15:193-204

Canning-Clode J, Sepúlved P, Almeida S (2020) Monteiro J (2020) Will COVID-19 containment and treatment measures drive shifts in marine litter pollution? Front Mar Sci 7:691

Czigany T, Ronkay F (2020) The coronavirus and plastics. Express Polym Lett 14:510-511

de Amorim JDP, de Souza KC, Duarte CR, da Silva Duarte I, de Assis Sales Ribeiro F, Silva GS, de Farias PMA, Stingl A, Costa AFS, Vinhas GM et al (2020) Plant and bacterial nanocellulose: production, properties and applications in medicine, food, cosmetics, electronics and engineering. A review. Environ Chem Lett 18:851-869

Fadare OO, Okoffo ED (2020) Covid-19 face masks: a potential source of microplastic fibers in the environment. Sci Total Environ 737:140279

Fawzy S, Osman AI, Doran J, Rooney DW (2020) Strategies for mitigation of climate change: a review. Environ Chem Lett 18:2069-2094 
Gunarathne V, Ashiq A, Ramanayaka S, Wijekoon P, Vithanage M (2019) Biochar from municipal solid waste for resource recovery and pollution remediation. Environ Chem Lett 17:1225-1235

Han J, Zhang X, He S, Jia P (2020) Can the coronavirus disease be transmitted from food? A review of evidence, risks, policies and knowledge gaps. Environ Chem Lett. https://doi.org/10.1007/ s10311-020-01101-x

Haward M (2018) Plastic pollution of the world's seas and oceans as a contemporary challenge in ocean governance. Nat Commun 9:667

Ibn-Mohammed T, Mustapha KB, Godsell J, Adamu Z, Babatunde KA, Akintade DD, Acquaye A, Fujii H, Ndiaye MM, Yamoah FA et al (2021) A critical analysis of the impacts of COVID-19 on the global economy and ecosystems and opportunities for circular economy strategies. ResourConservRecycl 164:105169

Klemeš JJ, Fan YV, Tan RR, Jiang P (2020) Minimising the present and future plastic waste, energy and environmental footprints related to COVID-19. Renew Sustain Energy Rev 127:109883

Kosheleva RI, Mitropoulos AC, Kyzas GZ (2019) Synthesis of activated carbon from food waste. Environ Chem Lett 17:429-438

Lichtfouse E (2009) Climate change, society issues and sustainable agriculture. In: Climate change, intercropping, pest control and beneficial microorganism; sustainable agriculture reviews, vol 2. Springer, Berlin, pp 1-7. https://doi. org/10.1007/978-90-481-2716-0_1

Lichtfouse E (2010) Society issues, painkiller solutions, dependence and sustainable agriculture. In: Sociology, organic farming, climate change and soil science; sustainable agriculture reviews, vol 3. Springer, Berlin, pp 1-17. https://doi. org/10.1007/978-90-481-3333-8_1

Lichtfouse E, Schwarzbauer J, Robert D (2012) Social chemistry. Environ Chem Lett 10:1-4. https://doi.org/10.1007/s1031 1-011-0333-3

Meeks D, Hottle T, Bilec MM, Landis AE (2015) Compostable biopolymer use in the real world: stakeholder interviews to better understand the motivations and realities of use and disposal in the US. ResourConservRecycl 105:134-142

Milios L, Holm Christensen L, McKinnon D, Christensen C, Rasch MK, HallstrømEriksen M (2018) Plastic recycling in the Nordics: a value chain market analysis. Waste Manag 76:180-189

Morin-Crini N, Lichtfouse E, Torri G, Crini G (2019) Applications of chitosan in food, pharmaceuticals, medicine, cosmetics, agriculture, textiles, pulp and paper, biotechnology, and environmental chemistry. Environ Chem Lett 17:1667-1692

Nanda S, Berruti F (2020) Municipal solid waste management and landfilling technologies: a review. Environ Chem Lett. https://doi. org/10.1007/s10311-020-01100-y

Nanda S, Berruti F (2020b) Thermochemical conversion of plastic waste to fuels: a review. Environ Chem Lett. https://doi. org/10.1007/s 10311-020-01094-7

Naqash N, Prakash S, Kapoor D, Singh R (2020) Interaction of freshwater microplastics with biota and heavy metals: a review. Environ Chem Lett. https://doi.org/10.1007/s10311-020-01044-3

Nithya R, Sivasankari C, Thirunavukkarasu A (2020) Electronic waste generation, regulation and metal recovery: a review. Environ Chem Lett. https://doi.org/10.1007/s10311-020-01111-9

Olivieri F, De Capitani C (2020) Additive manufacturing for biodegradable polymers. In: Marturano V, Ambrogi V, Cerruti P (eds)
Sustainability of polymeric materials. De Gruyter, Berlin, pp 235-252. ISBN: 9783110590586

Padervand M, Lichtfouse E, Robert D, Wang C (2020) Removal of microplastics from the environment. A review. Environ Chem Lett 18:807-828

Patrício Silva AL, Prata JC, Walker TR, Duarte AC, Ouyang W, Barcelò D, Rocha-Santos T (2021) Increased plastic pollution due to COVID-19 pandemic: challenges and recommendations. Chem Eng J 405:126683

Prata JC, Silva ALP, Walker TR, Duarte AC, Rocha-Santos T (2020) COVID-19 Pandemic Repercussions on the Use and Management of Plastics. Environ Sci Technol 54:7760-7765

Prideaux B, Thompson M, Pabel A (2020) Lessons from COVID19 can prepare global tourism for the economic transformation needed to combat climate change. Tour Geogr 22:667-678

Qasim U, Osman AI, Al-Muhtaseb AH, Farrell C, Al-Abri M, Ali M, Vo D-VN, Jamil F, Rooney DW (2020) Renewable cellulosic nanocomposites for food packaging to avoid fossil fuel plastic pollution: a review. Environ Chem Lett. https://doi.org/10.1007/ s10311-020-01090-x

Sanchez-Rexach E, Johnston TG, Jehanno C, Sardon H, Nelson A (2020) Sustainable materials and chemical processes for additive manufacturing. Chem Mater 32:7105-7119

Sarkis J, Cohen MJ, Dewick P, Schröder P (2020) A brave new world: lessons from the COVID-19 pandemic for transitioning to sustainable supply and production. ResourConservRecycl 159:104894

Sharma VK, Jinadatha C, Lichtfouse E (2020) Environmental chemistry is most relevant to study coronavirus pandemics. Environ Chem Lett 18:993-996

Sun S, Han J (2020) Unflushable or missing toilet paper, the dilemma for developing communities during the COVID-19 episode. Environ Chem Lett. https://doi.org/10.1007/s10311-020-01064-z

Tofa TS, Kunjali KL, Paul S, Dutta J (2019) Visible light photocatalytic degradation of microplastic residues with zinc oxide nanorods. Environ Chem Lett 17:1341-1346

Vanapalli KR, Sharma HB, Ranjan VP, Samal B, Bhattacharya J, Dubey BK, Goel S (2021) Challenges and strategies for effective plastic waste management during and post COVID-19 pandemic. Sci Total Environ 750:141514

Wang Z, Qin Y, Li W, Yang W, Meng Q, Yang J (2019) Microplastic contamination in freshwater: first observation in Lake Ulansuhai, Yellow River Basin, China. Environ Chem Lett 17:1821-1830

Wojnowska-Baryła I, Kulikowska D, Bernat K (2020) Effect of biobased products on waste management. Sustainability 12:2088

Wuyts W, Marin J, Brusselaers J, Vrancken K (2020) Circular economy as a COVID-19 cure? ResourConservRecycl 162:105016

You S, Sonne C, Ok YS (2020) COVID-19: resource recovery from plastic waste against plastic pollution. Cogent Environ. Sci. 6:1801220

Publisher's Note Springer Nature remains neutral with regard to jurisdictional claims in published maps and institutional affiliations. 